UCRL-101186

PREPRINT

\title{
Microwave Tokamak Experiment: An Overview of the Construction and Checkout Phase
}

\author{
D. D. Lang and H. H. Bell
}

ar

$\mathrm{OCr} 101989$

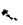

This paper was prepared for submittal to the IEEE 13th Symposium on Fusion Engineering Knoxville, Tennessee

October 2-6, 1989

September 28, 1989

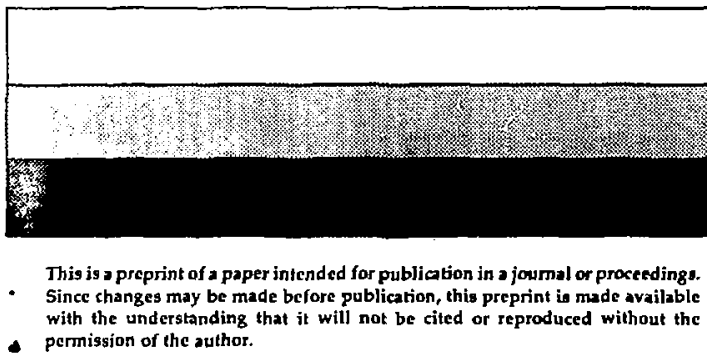

\section{DISCLAIMER}

Thes repurt was prepared as an accosun! of work sponsored by an agency of the United States Government Neither the United Stales Government nor any agency thereof, nor any of their employees, makes any wartanty, express or implied, or assumes any legal liability of responsi. process - isclesed, ur represents that. ur usefulness of any information, apparatus, product, or ence hercin to any represents that ifs use would not infringe privalely owned rights. Refermanufacturer. at specific commertial product, process, or service by trade name, irademark, mendation, ar lavurng by the lout necessarily constilute or imply in endarsement, recomand opinuns, of aunurs the United Stales Government or any agency thereor. The views United Siates Government ar any agencer therefo necessitrily statc or reflect those of the 


\author{
D. D. Lang and H. H. Bell \\ Lawrence Livermore National Laboratory \\ P.O. Bax 5511, L-636 \\ Livermore, CA 94551
}

DE90 000834

\section{Atstract}

At Lavrence Livermore National Laboratory (LLNL) we constructed and presently operate the Microwave Tokamak Exptriment (MTX) to demonstrate the feasibility of using microwove puises produred from a free electron laser (FEL) to provide electron cyclotron heating (ECH) for use in tokamaks, particularly high-field machines. The MTX consists primarily of the ALCATOR $C$ tokimak and power supplies that were documented and disassembled at the Massachusetts Institute of Technology (MIT) and shipped to LLNL in Aprí 1987. We made many additions, including a new prinary power system from the Magnetic Fusion Test Facility (MFTF) substation, a new commutation system, a subsiantually upgraded seismic support systen for earthquake loading, a fast controls system for use with the FEL, a new data-3cquisition system, and a new vault facility. We checked out these systerns and put them into operation in October 1988; we athices the first plasma in November 1988.

We have also constructed and installed the microwave transmisstun system and the local microwave system to be used w')th the FEl. These' systens transmit the microwaves to MTX quasi-ipptically through an svacuated tube. The ongoing plasma operatwons. both with and without FEL heating are described in a cimpanion paper. ${ }^{1}$

\section{iniroduction}

LL.NL, as part of the Strategic Defense Initiative, has been the major developer of FEl.s driven by linear induction-accelerated electron beams. The demonstration of microwave production by an FEL in 1966 led us to propose the MTX in July 1986 (Ref. 2). MTX was funded in April 1987. The major device fabrication was completed in Septemter 1988, and the first plasma was obtained in vocumber 1988

MTX has twa main purposes: (1) t. Itmonstrate the lechnoleng and physics of plasma heating with a micrownve FEL and (2) to explore current drive and other ECH applications in a toka mak. $\mathrm{ECH}$ applications have resulted in improved stability and confinement in tokamaks, and these improvements are well documentid In the past, micruwaves that have been used for ECH in magnets fusiun niachines have been produced by gyrotrons at frequences up to 60 Cllt and continuous-duty power levels of a few hundred kilowatls. The current state of the art has produced gyrutrons that operate at $140 \mathrm{CHz}$ with $20-\mathrm{ms}$ pulses at cutput piwers if $410 \mathrm{kWf}$ Further development of higher-frequency and higher-purver gyrotruns is needuc for fulure magnetic fusion devitus, but this is difficult due to the high heat loads associoled with these power levels and the small watelenglhs $(1 \mathrm{~mm}$ at 250 (ii i2) Se'e Ref 2 tor a more complete description of the physics. MIX has coupled the Experimental Test Accelerator II (FI A ll! with the Elet trun laser Facility II (ELF II) to what was finnerly the A!.CATUR C tokamak from MIT. (The use of existing nachnes enabled us to produce physics results more quickly, with d cust savings) E[ A II/EI_F II is designed to product 2-GW merowaves in $50 . \mathrm{ns}$ pulses, at a repelition rate of $5 \mathrm{kHz}$ for half a scrums, fir an average power of $2 \mathrm{MW}$ at frequencits of 140 and 23ilchts

\section{MTX Major Dequice Fabrícation}

MTX is located at LLNL in Building 431 , in an area previously used for MFSF-B, next to the ETA II facility. The overall experimental facility is shown in Fig. 1.

The tokamak is located inside a new experimental yault. The microwaves produced in the FEL are transmitted to, and launched into, the tokamak by the microwave transmission system. 7he control room and the local data-acquisition system are located on the second floor, to the north of the experimental vault.

\section{Tokamak Syslems}

The construction phase of our price-t began when we traveled to MIT, where we documented, disassembled, packaged, and shipped the tokamak and power supplies to LLNL (shipping required 14 trucks). This job is fully described in Ref. 3 . We then modified the tokamak support system to raise the machine to a centerline height of $10 \mathrm{ft}$, which provides better diagnostic access under the machine, and we upgraded the complete support system to handle seismic loads. Next, we examined the toroidal field magnet restraining clamps and Belleville washers (which provide inward clamping for individual bitter plates); we changed the threads to eliminate thread failures and replaced broken Belleville washers. We continued to modify the equipment:

- Rebuitt the main transformer ohmic heating coil becouse arcing had occurred during operalion at M!T.

- Rebuilt the fiberglass eryostat that provides thermal insulation for the liquid-nitrogen-cooled magnets.

- Modified the MFTF-B liquid nitrogen system to provide liquid nitrogen to the recirculating system obtained from MIT.

- Insialled a new vacuum system on the tokamak.

- Reinstalled the MIT discharge cleaning system, together with a new gas fueling system.

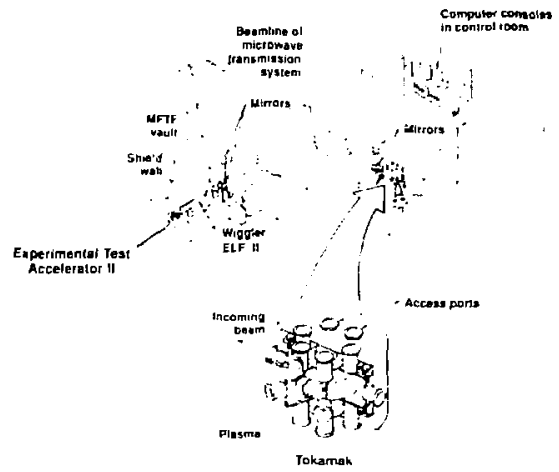

Figure 1. The Microwave Tokamak Expesiment (MTX) is located in Building 431, close to the Experimental Test Acceleralor II.

\footnotetext{
- W'ork performed under the auspices of the U.S. Department of Energy by the Lawrence Livermore National Laboratory under contract number W.7405-Eng-48.
} 


\section{Facilities and Grounding}

After a new concrete floor was poured that provided cable and diagnostic access ducts to a sunken area under the toksmak, wo constructed a new l-ft-lhick concrete shield wall around the 41- by 44-ft experimental are, We added cable tays, cooling waler, compressed air, ac power, and cominunications.

We tonk care to nuaintain the overall graunding plan. 4 All of the walls and the noor, including all attached hard ware, are connected to a single ground plane. The reinforcing steet in each of the concrete sections is isolated from every other section. None of the facilities has elect rical connextions froin one section to another; we did this to minimize etddy currents that can be induced during commutation of the ohrtic heating nugrtels. All individual ground planes are connected tc a single-point ground located in the center of the vault. We alsu constructed new platforms in the MFTF. B vault to house the ohmic healing power supplies and the romnu lation equipment.

\section{Afagnet Power Systen:}

At MIT, the primary ac power for the magnet power system was provided by a motor generator set. At LLVL, we used the MFTF-B substalion (230 k $V^{\prime}, 250 \mathrm{~W}$. 1 ) to provide the primary ac power because this subialion is lied to a very stiff part of the Califomia power grid. In underground ducts and cererhend cable trays we installed new ac freder cables from the substation to Building 431. We installed ne'w switchgear in tle substation, in addition to a second set of switchgenr at Building 431 , which was used to de-energize the power supplies belween shots. The toroidal pon'er supplies will provide $120 \mathrm{kA}$ for the 12 -tesh tokamak nuns or $70 \mathrm{kA}$ for the 5-tesla ruiss. The installation of the mignet power systen is described in Ret 5

Using parts of the .4IT bus structure, we constructed new $\mathrm{dc}$ bus sysiens for the toroldal and ohmic heating power systens.
The olinic heating power supplics proviste a current swing in the olmic heating magnets from $+20 \mathrm{kA}$ to $-20 \mathrm{kA}$, half the total capability that was available at MII. Wed.eignet and built a new olmic heating commutation system, using the commutation resistor from MIT; this is describud in Ref. 6.

\section{Danta Arguisition and Conlrol S) stcmis}

This is a new system that was under development at LLNL for use on any of the magnetic fusion experiments. The hardware includes a DEC VAX clusler (wwth an 8200 and an 8400), it workstations, and HP deshlop compulers, all interfaced with CAMAC crates. We are using commerchal sutfware in addition to packiges from MIT. Oak Ridge National Lollorntory (OKNL), and LLNL.

The plasma dingnostic data from $\mathrm{M}[\mathrm{X}$ is acquirct by this expandable, distributed, multi-vento: compuler network. The front-end cquipment in Building, 431 is linked to the Magnetic Fusion Energy (MFE) computer center in Building 543 via fiber optics. From there, the data can be viewed or antyzed from any terninat in the MJE area. The data can be translerred lo the National Magnetic Fusion Energy Computer Center for additional anilysis. This system is described in more delail in a companion paper?

The instrumentation and control system uses miny of the components from MIT, with substantial rework, and incorporates the new LLNL magnet-temperature nronitors, we switchgear controls, personnel interlock system, conmunkations system, and fast timing system. 8

\section{Plasma Dingnostics}

The plasna diagnostics on MlX are listed in Table 1 . The mechanical porlions of the suft $x$-ray array and the bolorieters were obtained from MIT as part of A.CATOR C. All of the other diagnostics are new or recanstructut from diagnostics used on wither the Tandem Mirrar Experintent- $L$ ipgrade $(T M A-L)$ ar from $M I F I F-B$

TABLE 1.

\section{MTX DIAGNOSTICS LIST}

\begin{tabular}{|c|c|c|}
\hline Diagnustic & Measurement & Instrutnerit Deserriptast \\
\hline \multicolumn{3}{|l|}{ In Placi } \\
\hline $\mathrm{FIR}$ interterometer & $n(r)$ & 15 radial chotsts \\
\hline Elextron eyclotron emission & $T_{e}(r)$ & Michelson interferonseler \\
\hline Magnetic loops & $\mathrm{I}_{\mathrm{L}} \mathrm{V}$-loop, MHD beta-p & $58 \mathrm{low}$ ps in M'TX \\
\hline ELiV' SPREFD spect rometer & Impuraties & $100-1000$ angstrom range \\
\hline Solf $x$ - ray array & $T_{e}$, sawteeth & 16-channel P'IN dicude drTis \\
\hline l.imiles $\times$ ray & Electron tail, disruptions & Single Nal detedor \\
\hline Visble' Bremsstmhiung & $Z_{e i f} n_{e}$, plasma posilion & 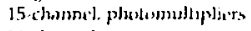 \\
\hline Kulometers & Enurgy confinement & 16-channel array \\
\hline l'harma camera & Plasma position, $\mathrm{H}_{\mathbf{a}}$ & 76-ms-resolution sulets \\
\hline Fast ion gauge \& $R G A$ & Gas pressure, impurities & \\
\hline Thomson sratiering & $T_{\mathrm{d}}(r), n_{\mathrm{e}}(\mathrm{r})$ & Single-pulse ruby lacer \\
\hline If alpha detexlors & $H_{a}$, breakdown & Fiber and pholomuluplater \\
\hline JAERI fast soft $x$ ray & FEL hot electrons & Fast-tine -response thistes \\
\hline JAERI neutron & lon temp. fusion produrts & Fast and slow time rtsponst \\
\hline last loops & FEL. hot ulectrons & Small loop inside lonis \\
\hline Microwave detectors & For, rel, trams FEL Power & Rexeiver, photen drag del \\
\hline Calonmiter & FEl profile inside tokaniak & 46 thermator channels \\
\hline \multicolumn{3}{|l|}{ future Insiruments } \\
\hline FIR scattering & Fluctualions, transport & JAERI collaboritiun \\
\hline FIR polarimetry & Plasina cut rent profiles & Add ais to interferonieter \\
\hline$x$-ray speclrometer & Ion tempe:alure & Curved crystal spectrometer \\
\hline Fast ECE polychromator & $\mathrm{T}_{\mathbf{e}}(\mathrm{r})$ during $\mathrm{F} \cdot \mathrm{EL}$ & U. of Maryluad instrument \\
\hline Fast Fabry-Perot ECE & $T_{e}$ al two loc during FEL & Split signal from Michulson \\
\hline Fast LCE iadiometer & Inside view of hot electrons & |AFRI instrıment \\
\hline
\end{tabular}


The ' thomana satteng system was constructed from components from the lM-L system, with a new laser table, spalial filter, input uptics, new viewing oplics, and alignnent system. The far infrared interferometer (FIR) uses a $\mathrm{CO}_{2}$ laser-driven far infrared hser purthased tor MFTH.B The FIR optical tower ${ }^{9}$ is built with composile fiberglass and custom-formed stainless steel channels; il is configured to minimize the induced eddy currents in the metal portion. This is done to maintain the relative position of the fiberglass optical tables above and below the machine to within 0.000 in. $A$ . uniter of diagnustics are provided through the DOE/LLNL-Japan Atime Energy Rescarch Institute (JAERJ) collaboration. These inslude the fast suft x ray array and the high power nicrowave dump.

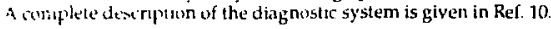

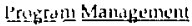

MTX is divided into seven main areas of work: tokamak whtents, magnet power, data acquisition, controls and instruneitlutum, diagulustles, facilities, and program managenuent. We wate detalited cost and schedule eslimates for each of the utsystems, based on the overall financial constraints. From these, "e sel the overall propert budget and major milestones. The critical paths $f_{1}$ ir constructwin were the magnet power subsystem and the facility. and tle installation of the tokaniak systems.

()ur methud tor managing the major device fabrication of the $M I X$ projet was goal-oriented and nilestone-driven. Within the ma in work breakdown structure, we developed detailed work treakdow ns, logether with applicable requirements. We made letalcit rost and schertule estinules for each subsystem, and we sontured the' progrt'ss of each subsystem against those projections - 'e asingned thajur provect milestones to each of the major wbystemts and repurted these to the Department of Energy

Bexause of finamial limitalions, we kept upgrades to a min..num (1) any svstem, and we made greal efforts to use existing fHithmalu abalable lin the magnetic fusion community. We used juipment trom TNA -U, MFIF-B, ALCATOR C, Dou:blet il[-D IDIII\%, and a pellet injector that had been used on the Princeton "arge liurus (I'TT) and "Texas Experimental Tokanak (TEX'). The "nly task in the prupussl we did not complele was installation of the wer hytrid hedemg sy'stem; we had to drop this because of bud., 4 ants

We munturent the design of the various systems in prelimi.Al a and find destgn reviews. A more complete description of the
TABLE 2.

MAJOR DEVICE FABRICATION TOTAL COSTS

\begin{tabular}{llrrr}
\hline & \multicolumn{1}{c}{ Subsystem } & FY87 & $\underline{\text { Fr8g }}$ & $\underline{\text { Total }}$ \\
\hline & & 430 & 444 & 874 \\
1.0 & Tokamak systems & 854 & 1,933 & 2,787 \\
2.0 & Magnet power & 37 & 175 & 212 \\
3.0 & Lower hybrid heating & 58 & 1,204 & 1,262 \\
4.0 & Program management & 27 & 38 & 65 \\
5.0 & Data acquisition & 38 & 267 & 305 \\
6.0 & Controls \& instrunentation & 121 & 1,286 & 1,407 \\
7.0 & Diagnostics & 651 & 81 & 732 \\
8.0 & Facilities & 0 & 0 & 0 \\
9.0 & Systentesting & 244 & $\underline{712}$ & $\mathbf{9 5 6}$ \\
& Administrative overhead & 2,460 & 6,140 & 8,600 \\
\hline
\end{tabular}

progmm managensent is given in Ref. 11 . The major device fabrication cosls are shown in Table 2.

\section{ELF II and Microwave Transmission Syslem}

While the initial ohmic heating operation of the tokamak was under way, we completed installation of the ETA II wiggler (ELF II) and the microwave transmission system. This connection (shown in Fig. 1) completed the handware required for the phase 1 FEL heated-plasma experiments.

The microwaye transmission system uses a 20 -in.-diameter evacuated tube and a series of metal mirrors to transmit the microwave pulses in a quasi-optical mode from the ELF II into the tokamak. The microwave transmission system is shown in detail in Fig. 2. The microwaves amplified by the FEL action in the wiggleI are broadcast from the end of the wiggler in an antenna pottern that is caplured by the first turning mirror.

This first mirror focuses the microwaves and samples the amount of both forward and reflected power incident on it. On mirror 4, the microwave beam is focused down to fit through the 4 - by $30-\mathrm{cm}$ slot to hit the plasma. Typical transmission efficiencies are in the range of $87 \%$ of the microwave produced by the wiggler, with most of the losses occurring on the first mirror. Testing of the

\section{Microwave Transmission System}

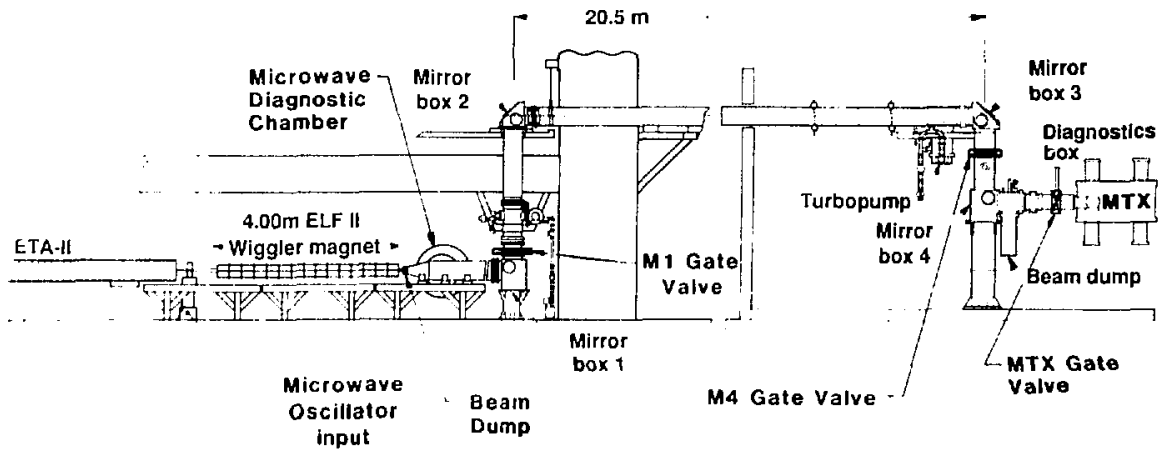

1'gare 2. The mictowave transmission system ties ETA-It/ELF-ll to MTX. 
FEL is done by swinging a mowable mitror into the path of the mictowaves as they exit the wiggler, ant diverting them into the load tank, where they are nonitored for power, frequency, and mode.

The aligntnent of the transmission system is done with a laser that is aligned to the centerline of the wiggler using linenreffect photo diodes. The laser is then ihet through the system, where it is reflected off the mirrors. The position of the laser is monitored by insertable probes at vatious mirrors and inimediately in front of the tokamak siot. Many last microwavediagnostics are located between murror box 4 and the toiamak. These are described in delail in Refs. 1 and 12

\section{Completion}

The MDF inslallation was completed in July 1988. The Engineering System Test-the last MDF activity-was completed on schedule in September 1988.

\section{Cherknu!}

In September 1988 all individual systems had been operaled to their required ratings. The magnet system has been operated to toroidal fields of 9 tesia ( $120 \mathrm{kA}$ from the toroidal power supplies); the ohmic healing colls had been operated to their rated $17 \mathrm{kA}$; and all plasma positioning coils had been un to their ratcd curtents. The vacuum system had been baked, discharge-cleaned, and operated to obtain vacuuns to $10^{-8}$ Tor.

The cortrols and instrumentation syslear hat been used during the tests of the rigenet system; the data acquisition system had acquired the various magnet durremith and the diagnostics data. The MDF cost was $\$ 86$ million Breakdown of the cost by subsysletn is given in Table 2.

As stated before, the lirst plasma was obtained in November 1988. A companiun paper describes the operation of MTX since that time and the oforatws of MIX with FEL.

\section{Jiw Construclion}

We are constructing a pellet injector with parts of the old PLT pellet injeclor used on TEXT. We have incorporated into this injector the new "pipe gun" design from : he Pellet Injector Croup at Oak Ridge Vahonal Laboralory. It is a 4 -shat injector, capable of shooting pellets ranging from 0.75 to $1.55 \mathrm{~mm}$ in dianeter. This pellet injector should be ready to start shooting pellets in October 1989. It will bo instailed on the tokamak for pellet-fueled experiments startung in 'vou t'mber 1989, after tlic present FEL experiments have been completed

\section{Acknowledgments}

These tnembers of the engineenng staff were responsible for the successful construction and checkout of MTX: C. A. Brooksby, D $\curlyvee$ Butner, B. Felker, S W. Ferguson, S. M. Hibbs, M. C. Jackson, D E l'etersen, $G \subset$ Preckshot, B. W Rice, and N. R. Sewall We trstrially acknowledge Steve Allen's contributions duting the cher-kout phase (Steve is the Group Leader for MTX Operations)

The" duthors also thank the rest of the engineering staff and the physies stiff- all coniributed to the sucessiful ronstrurtion of $M \Gamma$.

\section{Reforences}

1. M. C. Jackson, "Microwave Tokamet $\mathrm{vw}$ ziment (MTX) First Year of Operation and Future Plans," in these Procedings.

2. K. I. Thomassen, Free-Electron Laser Experiments in Alator C, Lawrence Livernore Nalional I abonatory, Livermore, CA, LLLPROP-00202, July 1986

3. 5. M. Hibbs, "Bringing the Mountain to Mohammed: The Relocation of Alcalor-C," Lawrence Livermorr" "Lational Laborntory, Livernore. CA, LCRL-97514, Octoter 1987.

4. H. H. Bell "MTX Facility and Machine Cirounding l'lan," Proceedings of $12 t h$ Symposium on Fusion Enginesing, 1987 (Monterey, Calis, Lawrence livenrore Nalional laboratory, Livermore, CA, UCR1-96t,53, Oxtober 7987.

5. M. C. Jackson, "Magnet Power Systern for the Microwave Tukamak Experiment (MTX)." lrocetatings of 12 th Symposium an Fusion Engineering 1987 (Monterey, Colif.), Lawrence Livennore National Labontory, Livermore, C.A, UCKL-9665i. October 1987

6. M. C. Jackson, "Microwave Tokamak Lxperiment (M17X) Ohmic Heating System," in these Proceedings.

7. D. N. Butner, "The MTX Iata Acquisition Syslem," in these Proceecdings:

8. D. E. Peterson, "Irecision Timung/inter]ocks System for FEL, Healing Experinents on MYX." in these [inceedings.

9. C. A. Brooksby, "Dlsign of a Far Infrarcel Interferumeter Diagnostic Support Structure," Prugeudings of $12 \mathrm{~h}$ Symposiun on Fusion Engincering, $19 \mathrm{AB}$ (Montirey, Calif I, Lawrence Livermore National Laboratory, l.1vemore, CA, UCRL-97483, Oetuber 1987.

10. B W. Rice, "MTX Plasma I Jiagnustics System," I'rouecedings of 12th Symposium on Fusion Engunetring, 1987 (Monlerey, Calif , Lawrence Livemore Nationa] Laboratory, Livermore, CA, LCRL-96654, October 1987.

i) K. I. Thomassen, Microwave Tokanuk Experiment Administrative Plan Lawrence Livennore National Laboratory.

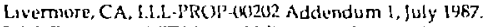

12 S. W. Ferguson. "MTX/FIF II Mic ruwave Pnwer Measu rements

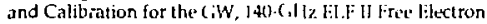
Laser," in these Procecedings. 